\title{
Geç Başlangıçlı Alzheimer Hastalığı ve Hepatosellüler Karsinom ile İlişkili Ortak Moleküler Yolakların ve Anahtar Biyobelirteçlerin Biyoinformatik Analizlerle Araştırılması
}

\author{
Dilek PİRIM, Ecem Buse YILMAZ \\ Bursa Uludağ Üniversitesi, Fen-Edebiyat Fakültesi, Moleküler Biyoloji ve Genetik Bölümü, Bursa.
}

\section{ÖZET}

Son zamanlardaki çalısmalarda Alzheimer hastalığ $(\mathrm{AH})$ ve kanser arasında bir bağlantı olduğu ortaya konmus fakat ortak mekanizmayı açıklayacak yeterince kanıt mevcut değildir. Bu bağlantıyı araştıran birçok çalışmada özellikle meme, prostat ve akciğer gibi kanser türleri ile AH arasında ters ilișki olduğu gösterilmekle beraber hepatosellüler karsinom (HCC) ve AH arasındaki ilișki henüz aydınlatılmamıștır. Bu çalışmada, geç başlangıçlı AH (LOAD) ve HCC ile ilişsili RNA dizileme (RNA-seq) verilerini biyoinformatik araçlarla analiz ederek iki hastalığın patogenezinde etkin olması muhtemel ortak moleküler yolakları, ortak diferansiyel olarak ifade olan genleri (DEG) ve aday anahtar miRNA'ları tespit etmeyi amaçladık. RNA-seq veri setleri NCBI-GEO veri tabanından alınarak GREIN web uygulaması ile analiz edildi. Ortak DEG'ler tespit edilerek, fonksiyon zenginleştirme analizleri NetworkAnalyst ile yapıldı. Network görselleştirme ve hub gen tespiti Cytoscape programı ile gerçekleștirildi. Hub genleri hedef alan miRNA'lar mirDIP veri tabanı ile belirlendi. Analiz sonucunda iki veri setinde ortak disregüle olan 33 DEG tespit edildi ve network analizinde iki hastalığın moleküler etiyolojisinde olası rolü olan ortak 5 hub gen (HLA-A, HLA-C, TRIM31, HLA-DQB2, HLA-DRB) belirlendi. Ortak DEG'lerin immun sistemle ilişkili moleküler yolaklarda ve biyolojik süreçlerde etkin olduğunu gözlemlendi. Ortak hub genlerin koregülasyonunda potansiyel düzenleyici rolleri olabilecek iki hastalıkla da ilişkili olduğu tahmin edilen birçok miRNA bulundu. Sonuçlarımız, her iki hastalık için risk değerlendirmesi ve ilaç geliştirme yaklaşımları için kullanılabilecek ortak moleküler mekanizmayı in silico kanıtlarla vurgulamaktadır.

Anahtar Kelimeler: Alzheimer Hastalı̆̆ı. Hepatosellüler karsinom. MiRNA. Biyoinformatik; biyobelirteç. Hub gen.

Investigating the Common Molecular Pathways and Key Biomarkers Associated with Late-Onset Alzheimer's Disease and Hepatocellular Carcinoma by Bioinformatic Analysis

\begin{abstract}
Recent studies suggest a potential link between Alzheimer's disease (AD) and cancer yet lack of evidence exists to understand the shared mechanism underlying both diseases. Accumulating research investigating the association between AD and specific types of cancers such as breast, lung and prostate cancer claim inverse relationship between them however possible molecular relationship between $\mathrm{AD}$ and hepatocellular carcinoma (HCC) has not been well studied. In this study, we reanalyzed RNA-sequencing data sets related to late-onset AD (LOAD) and HCC to identify common differentially expressed genes (DEGs), molecular pathways as well as key miRNA regulators that may involve in the pathogenesis of both diseases. The data sets were retrieved from NCBI-GEO database and analyzed by GREIN web tool. Overlapped DEGs were identified and their functional enrichments were analyzed by NetworkAnalyst. Cytoscape software was used to visualize network and identify hub genes. MicroRNAs targeting the hub genes were also determined by mirDIP database. A total of 33 DEGs were found to be dysregulated in both datasets and five genes (HLA-A, HLA-C, TRIM31, HLA-DQB2, HLA-DRBI) were identified as hub genes that possibly involve in the shared molecular etiology of both diseases. Our analyses revealed that common DEGs are enriched in molecular pathways related immune system and multiple miRNA regulators are likely to coregulate the expressions of shared hub genes. The results emphasize in silico evidence of common molecular background for LOAD and HCC, which can be ultimately utilized for risk assessments and drug development approaches for both diseases.
\end{abstract}

Key Words: Alzheimer's disease. Hepatocellular carcinoma. MiRNA. Bioinformatic; biomarker. Hub genes.

Geliş Tarihi: 20.Mayıs.2020

Kabul Tarihi: 08.Temmuz.2020

* 4.Çukurova Hepatoselüler Karsinoma Kongresi'nde (27-

29 Şubat 2020, Adana) sözlü bildiri olarak sunulmuştur.

Dr. Dilek PiRiM

Bursa Uludağ Üniversitesi, Fen-Edebiyat Fakültesi,

Moleküler Biyoloji ve Genetik Bölümü, Bursa.

Tel.: 02242942835 - 05442507680

E-posta: dilekpirim@uludag.edu.tr

Yazarların ORCID ID Bilgisi:

Dilek PIRIM: 0000-0002-0522-9432

Ecem Buse YILMAZ: 0000-0002-3486-7994
Alzheimer hastalığ 1 (AH) hala dünya çapında demans ve yıkıcı beyin hastalıklarının en yaygın türü olarak bilinmektedir ${ }^{1}$. Genetik risk faktörlerinin AH klinik öncesi ve klinik evrelerinde önemli rol oynadığını gösteren kanıtlar her geçen gün artmakla beraber hastalığın halk sağlığı yükünü hafifletmek için daha fazla araştırma gerekmektedir ${ }^{2-5}$. Erken başlangiçlı Alzheimer Hastalığı (EOAD), AH'nin daha az yaygın formu olarak bilinir ve klinik bulgular 65 yaşından önce başlayarak hasta bireylerin teşhisi de daha erken dönemde olur. Geç başlangıçlı AH ise hastalığın en 


\section{Pirim ve E.B. Yılmaz}

sık görülen formudur ve genetik faktörlerle beraber çevresel faktörlerin de etkin olduğu heterojen bir etiyolojiye sahiptir, bu da doğru erken tanı ve tedavi seçeneklerinin geliştirilmesinde en büyük engele neden olur ${ }^{6}$. Bu sebeple, AH patogenezinde etkin moleküler yolakların ve biyobelirteçleri ortaya çıkarmak $\mathrm{AH}$ yönetimi için uygun tanı, risk değerlendirme ve tedavi yaklaşımlarının geliştirilmesi açısından son derece önemlidir.

Metabolik yolaklarda bozuklukların sebep olduğu obezite, dislipidemi ve diyabet gibi metabolik hastalikların AH gelişimi ile ilişkili olduğu bilinmektedir ${ }^{7-}$ 10. Ayrıca, son epidemiyolojik çalışmalarda $\mathrm{AH}$ ve kanser arasındaki bağlantıyı düşündüren ilginç kanıtlar da sağlanmıştır ${ }^{11-19}$. Verilerde çelişkili sonuçlar olmasına rağmen büyük bir çoğunluğu $\mathrm{AH}$ ve kanser arasında ters bir ilişki olduğunu öne sürerek farklı kanser türlerine sahip olan bireylerde $\mathrm{AH}$ gelişme risklerinin düşük olduğu fikrini ortaya $\operatorname{koyar}^{20,21} . \mathrm{Bu}$ konuyu araştırmak ve bu iki önemli küresel halk sağlığı sorununun temelinde yatan ortak mekanizmanın aydınlatılması son yıllarda araştırmacılar tarafından ilgi çeken bir konu olmaya devam etmektedir ${ }^{22,23}$.

Bu alanda yapılan çalışmalarda malign beyin tümörleri (TREM2, SPI1, CD33 ve INPP5D) ile ilişkili genlerin $\mathrm{AH}$ riskine katkıda bulunduğu gösterilmiştir ${ }^{24}$. Diğer bir çalışmada meme kanseri hastalarında $C D 33$ ve $C D 2 A P$ genlerindeki patojenik varyantların $\mathrm{AH}$ hastalığı için risk teşkil eden APOE varyantları ile beraber aktarıldığ gösterilmiş, meme kanseri ilișkili bilişsel gerilemede AH ile ilişkili APOE geninin önemi ortaya konmuştur ${ }^{25}$. Ayrıca, AD ve kanser hastalığı ile ilişkili miRNA'ların da iki hastalık için rolleri araştırılmış ve iki hastalık durumunda da anlatımları düzensizleşen miRNA'ların çoğunlukla anlatımlarının zıt yönde değişiklikler gösterdiğini belirten çalışmalar mevcuttur ${ }^{26,27}$. Bu alandaki mevcut bilginin daha fazla çalışmayla açıklığa kavuşturulması ilaç yeniden amaç- landırma, ilaç yeniden profillendirme, ilaç yeniden hedeflendirme ve kişiselleştirilmiş tıp yaklaşımları oluşturma potansiyeli açısından dönüşümsel tıp alanı için son derece önemlidir ${ }^{28,29}$.

$\mathrm{Bu}$ amaçla yapılan çalışmalarda $\mathrm{AH}$ ve farklı kanser türleri arasındaki ortak etiyolojiye dair kanıtlar olmasına rağmen hepatosellüler kanser (HCC) ve AH arasındaki ilişkiyi gösteren literatürde çalışma bulunmamaktadır. Bu çalışmada, AH hastalığının yaygın formu olan LOAD ve HCC arasındaki ortak moleküler etiyolojiyi araştırarak iki hastalığın yönetimi için tasarlanabilecek dönüşümsel tıp yaklaşımlarına veri oluşturmak amaçlanmıştır. Çalışmamızda in silico araçlar kullanarak LOAD ve HCC ile ilgili ortak biyolojik yolaklar, anahtar biyobelirteçleri ve regülatörleri araştırılmıştır.

\section{Gereç ve Yöntem}

\subsection{Veri erişimi ve diferansiyel gen ifade analizleri}

$\mathrm{Bu}$ çalışmada kullanılan RNA-seq veri setleri (GSE73708, GSE67333) Gene Expression Omnibus (GEO) veritabanından alınmıștır ${ }^{30}$. GSE73708, 4 HCC'e sahip birey ve 4 kontrol içerirken, GSE67333 veri setinde LOAD'a sahip 4 hasta ve 4 kontrol bulunmaktadır (Tablo I). Her iki veri setindeki vakalar ve kontroller arasındaki diferansiyel olarak ifade edilen genler (DEG'ler), GEO RNA-seq Experiments Interactive Navigator (GREIN) web platformu kullan1larak analiz edildi ${ }^{31}$. P-değeri $<0.05$ ve $\log 2 \mathrm{FC} \geq 2$ veya $\leq 2$ olan DEG'ler istatistiksel olarak anlamlı kabul edildi. Her iki veri kümesi için de istatistiksel olarak anlamlı DEG'ler karşılaştırılarak ortak DEG'ler çalışmanın ileriki aşamalarına dahil edildi (Şekil 1).

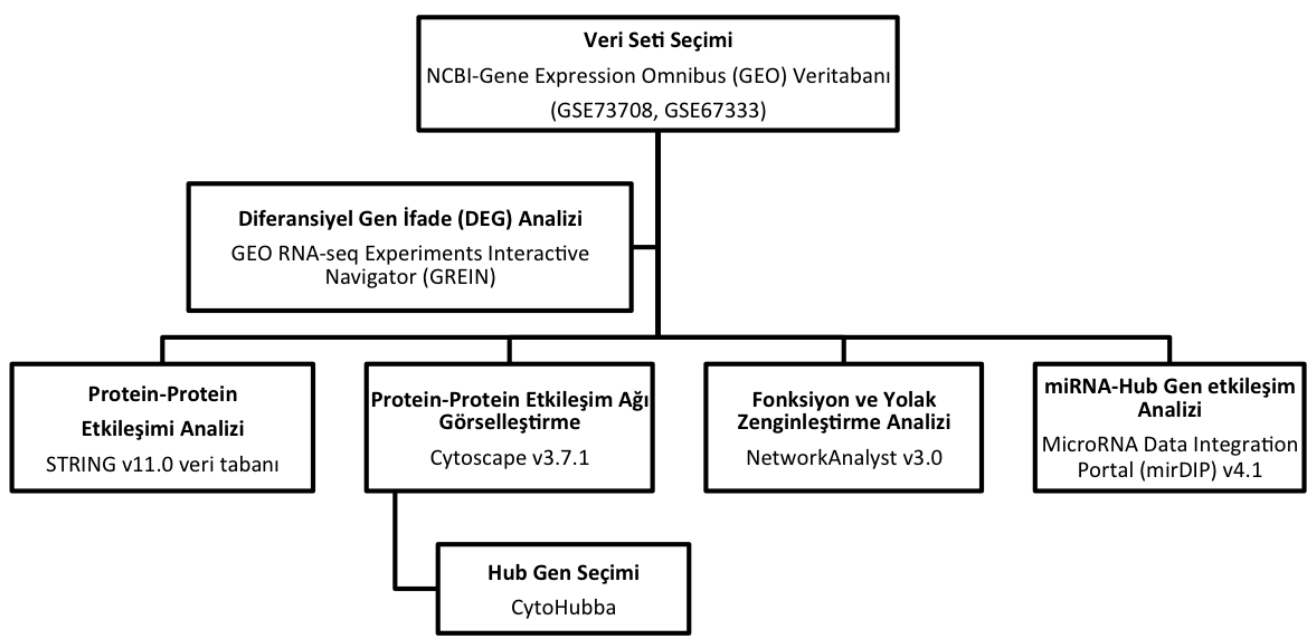

Sekil 1.

Çalışmanın metodolojik yaklaşımı 


\section{LOAD ve HCC İle İlişkili Ortak Moleküler Yolaklar}

Tablo I. Çalışmada analiz edilen GEO veri setleri

\begin{tabular}{|lcccll|}
\hline \multirow{2}{*}{ Veri Seti } & $\begin{array}{c}\text { Doku } \\
\text { Tipi }\end{array}$ & $\begin{array}{c}\text { Örnek Grup } \\
\text { Hasta } \\
\text { sayısı }\end{array}$ & $\begin{array}{c}\text { Kontrol } \\
\text { sayısı }\end{array}$ & Metod & Platform \\
\hline GSE73708 Karaciğer & 4 HCC & $\begin{array}{l}4 \text { Sağlıklı } \\
\text { kontrol }\end{array}$ & $\begin{array}{l}\text { RNA- } \\
\text { Seq }\end{array}$ & $\begin{array}{l}\text { Illumina HiSeq } \\
2000\end{array}$ \\
GSE67333 Hipokampus & 4 LOAD & $\begin{array}{l}4 \text { Sağlıklı } \\
\text { kntrol }\end{array}$ & $\begin{array}{l}\text { RNA- } \\
\text { Seq }\end{array}$ & Illumina HiSeq \\
\hline
\end{tabular}

2.2. Protein etkileşim ăg network analizi ve hub gen tanımlanması

İlk olarak, ortak DEG'ler, protein-protein etkileşimlerini (PPE) analiz etmek için STRING ${ }^{32}$ v11.0 veritabanına (https://string-db.org/) aktarıldı ve birleşik skor $>0.4$ seçilerek protein etkileşim ağ 1 oluşturuldu. A $\breve{g}$ görselleştirilmesi ve ağın topolojik özelliklerinin analizi Cytoscape yazılımında (Cytoscape v3.7.1) Cytohubba eklentisi kullanılarak yapilarak hub genler tespit edildi (Cytoscape v3.7.1). Cytohubba, 12 farklı puanlama yöntemi kullanarak proteinlerin etkileşimlerini hesaplar ve hub genler bu puanlamalara göre seçi$\operatorname{lir}^{33}$. Bu çalışmada tanımlanan "hub genler" topolojik analizde derece sıralamasında (ağ düğüm derecesi $\geq 4$ ) en üst ortak DEG'ler dikkate alınarak tanımlanmıştır ${ }^{34}$. Seçilen proteinler protein etkileşim ağında en fazla etkileşime sahip hub moleküllerdir.

\subsection{Ortak diferansiyel olarak ifade olan genlerin fonskiyonel analizleri}

İki veri setinde ortak DEG'lerin moleküler yolaklarda ve biyolojik süreçlerde kümelenmelerini ve fonksiyonlarını analiz etmek için NetworkAnalyst aracı kullanıld ${ }^{35}$. Fonksiyon zenginleştirme analizinde hipergeometrik teste göre $\mathrm{p}<0.05$ olan Kyoto Genler ve Genomlar Ansiklopedisi (KEGG) ve Gen Ontolojisi (GO) terimleri istatiksel olarak anlamlı kabul edildi.

\subsection{Ortak miRNA-hedef gen etkileşimlerinin tahmini}

MikroRNA'ların gen regülasyonunda önemli rolleri olduğu bilindiğinden çalışmamızda HCC ve LOAD'da aynı hub genleri hedef alan iki hastalıkta muhtemel ilişkili miRNA'lar MicroRNA Veri Entegrasyon Portalı (mirDIP) v4.1 veritabanı kullanılarak tespit edildi $^{36}$. Tespit edilen hub genler grup olarak veri tabanına yüklenerek 30 farklı algoritmadan gelen veriler entegre edilerek hub genleri hedefleyen miRNA'lar tahmin edildi.

\section{Bulgular}

\subsection{DEG analizleri ve ortak DEG'lerin tanımlanması}

GSE73708 ve GSE67333 veri setlerindeki RNA-seq verilerinin analizleri sonucunda HCC'de 2632, LOAD'da ise 255 DEG tespit edildi. HCC ve LOAD için tespit edilen DEG'ler karşılaştırılarak, protein kodlayan genlere karşılık gelen her iki hastalıkta için de ortak 33 DEG tanımlandı. Bunlardan 5'i HCC'de aşağı-regüle iken LOAD'da yukarı regüle olduğu, 10 DEG'in HCC'de yukar1-regüle ve LOAD veri setinde ise aşağı-regüle olduğu, 18 DEG'in ise her iki veri setinde de aynı yönde anlatım yaptığı tespit edildi. Tablo II, her iki hastalıkta da aynı ve zıt yönlerde düzensiz ifade edilen ortak DEG'leri göstermektedir.

\subsection{Protein-protein etkileşim ağının kurulması}

STRING veritabanı kullanılarak analiz edilen 33 ortak DEG'in PPE zenginleştirme P-değeri 2E-09 bulundu ve istatiksel olarak anlamlı ölçüde PPE ağı kuruldu. Ağ görüntülenmesi için Cytoscape kullanılarak ağın topolojik özellikleri Cytohubba ile hesaplanarak Tablo III'de gösterilmiştir. A ğ düğüm derecesi $\geq 4$ olan genleri hub genleri olarak kabul ettik ve bu şekilde iki hastalığın ortak yolaklarında etkin olduğu muhtemel 5 hub gen (HLA-DRB1, HLA-DQB2, TRIM31, HLA-C, $H L A-A)$ tespit ettik. Ayrica, 2 hub geninin (HLA$D R B 1, H L A-C)$ her iki veri setinde de aynı yönde düzenlendiğini ve 3 hub geninin (HLA-DQB2, TRIM31, HLA-A) HCC ve LOAD'da ters yönde düzenlendiğini gözlemledik (Tablo II).

Tablo II. LOAD ve HCC veri setlerinde tespit edilen ortak DEG'ler

\begin{tabular}{|l|l|}
\hline $\begin{array}{l}\text { Direction of the } \\
\text { deregulation of the DEG }\end{array}$ & Gene ID \\
\hline+ LOAD/- HCC & RAB25, TTN, GABBR1, HLA-DQB2, P2RY10 \\
\hline+ HCC/ - LOAD & $\begin{array}{l}\text { SLPI, MAPT, TRIM31, S100A8, S100A9, HLA- } \\
\text { A, DCANP1, HSPA1B, AGPAT1, BPIFA2 }\end{array}$ \\
\hline - LOAD/- HCC & AREG, HLA-DRB1, MARCO, C7orf34 \\
\hline+ LOAD/+ HCC & $\begin{array}{l}\text { PRRC2A, SULT1C2, EGFL8, CAPN11, } \\
\text { HSPA1A, NFKBIL1, UBE2C, HLA-C, MICA, } \\
\text { CDX1, SMPX, ISX, RHO, MAGEB17 }\end{array}$ \\
\hline$+:$ Yukarı regülasyon, -: Aşağı regülasyon \\
\hline
\end{tabular}

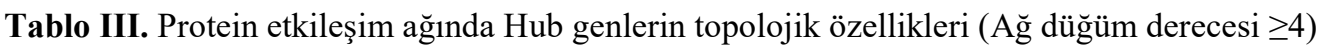

\begin{tabular}{|lcccccccccccc|}
\hline \multicolumn{1}{|c}{ Gen ID } & Betweenness & BottleNeck & Closeness & $\begin{array}{c}\text { Clustering } \\
\text { Coefficient }\end{array}$ & Degree & DMNC & EcCentricity & EPC & MCC & MNC & Radiality & Stress \\
\hline HLA-DRB1 & 186 & 17 & 11.28333 & 0.25 & 8 & 0.56839 & 0.17895 & 7.525 & 28 & 4 & 5.92763 & 186 \\
\hline HLA-DQB2 & 0 & 1 & 8.28333 & 1 & 4 & 0.56839 & 0.14912 & 6.74 & 24 & 4 & 5.25658 & 0 \\
\hline TRIM31 & 0 & 1 & 8.28333 & 1 & 4 & 0.56839 & 0.14912 & 6.792 & 24 & 4 & 5.25658 & 0 \\
\hline HLA-C & 0 & 1 & 8.28333 & 1 & 4 & 0.56839 & 0.14912 & 6.708 & 24 & 4 & 5.25658 & 0 \\
\hline HLA-A & 0 & 1 & 8.28333 & 1 & 4 & 0.56839 & 0.14912 & 6.806 & 24 & 4 & 5.25658 & 0 \\
\hline
\end{tabular}




\section{Pirim ve E.B. Yılmaz}

3.3. DEG'lerin moleküler yolaklarda ve biyolojik süreçlerde zenginleştirilmesi

HCC ve LOAD veri setlerinde ortak DEG'lerin KEGG yolak ve GO zenginleştirme analizi NetworkAnalyst aracında gerçekleştirildi. Ortak DEG'lerin kümelendiği en önemli $10 \mathrm{KEGG}$ terimi bağışıklık tepkisi ile ilişkiliydi ve en önemli terim "Antijen işleme ve sunum yolu" idi $(\mathrm{P}=4.83 \mathrm{E}-07)$ (Tablo IV). Tüm istatiksel olarak anlamlı KEGG terimleri Şekil 2'de gösterilmiştir. GO zenginleştirme analizi, ortak DEG'lerin çeşitli GO terimleriyle ilişkili olduğunu ve bunların özellikle immün cevaptaki rollerinin önemini ortaya koymuştur (Şekil 3). GO terimleri ile ilişkili en önemli biyolojik sürecin "doğal bağışıklık yanıtı" olduğu da gözlenmiştir ( $\mathrm{P}=5.89 \mathrm{E}-06)$ (Tablo V).

Tablo IV. Ortak DEG'lerin kümelendikleri en anlamlı 10 KEGG terimi $(\mathrm{P}<0.05)$

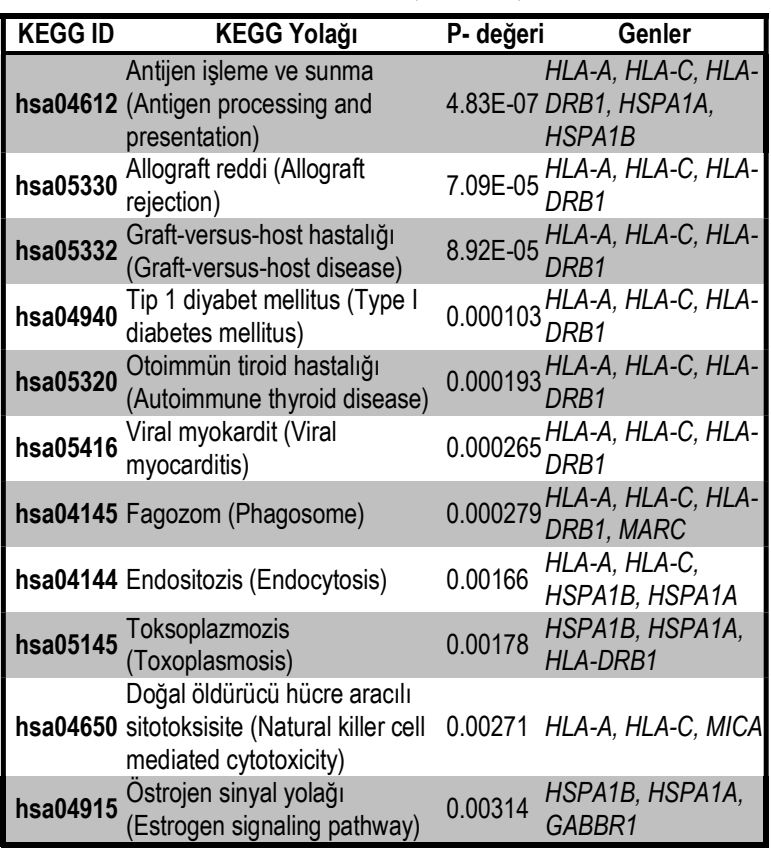

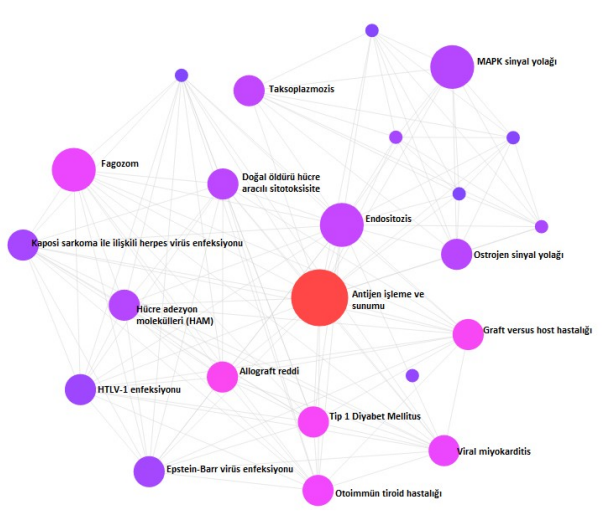

Sekil 2.

Ortak DEG'lerin kümelendikleri KEGG yolak terimleri $(p<0.05)$. Dairenin büyüklüğ̈̈ ilgili yolağın anlamlılık derecesiyle doğru orantılıdır. Kırmızı daire en anlamll yolăgl gösterir.
Tablo V. Ortak DEG'lerin kümelendikleri biyolojik süreçlerle ilişkili en anlamlı $10 \mathrm{GO}$ terimi $(\mathrm{P}<0.05)$

\begin{tabular}{|c|c|c|}
\hline $\begin{array}{c}\text { GO term ID: } \\
\text { Biyolojik süreç Terimleri }\end{array}$ & P-değeri & Genler \\
\hline $\begin{array}{l}\text { GO:0045087: Doğal bağışıklık } \\
\text { yanıtı (Innate immune } \\
\text { response) }\end{array}$ & $5.89 \mathrm{E}-06$ & $\begin{array}{l}\text { HLA-A, HLA-C, HLA-DQB, } \\
\text { HLA-DRB1, S100A8, } \\
\text { S100A9, MARCO, MICA }\end{array}$ \\
\hline $\begin{array}{l}\text { GO:0009581: Dış uyaranların } \\
\text { tespiti (Detection of external } \\
\text { stimulus) }\end{array}$ & 2.92E-05 & $\begin{array}{l}\text { HLA-A, HLA-DRB1, RHO, } \\
\text { TTN }\end{array}$ \\
\hline $\begin{array}{l}\text { GO:0009617:Bakteriye yanit } \\
\text { (Response to bacterium) }\end{array}$ & $3.28 \mathrm{E}-05$ & $\begin{array}{l}\text { HLA-A, HLA-DRB1, } \\
\text { S100A8, S100A9, MICA, } \\
\text { NFKBIL1 }\end{array}$ \\
\hline $\begin{array}{l}\text { GO:0006952: Savunma tepki- } \\
\text { sinin pozitif düzenlenmesi } \\
\text { (Positive regulation of defense } \\
\text { response) }\end{array}$ & 7.75E-05 & $\begin{array}{l}\text { S100A8, S100A9, MARCO, } \\
\text { MICA, NFKBIL1 }\end{array}$ \\
\hline $\begin{array}{l}\text { GO:0050776: Bağışıklık yanıtı- } \\
\text { nın düzenlenmesi } \\
\text { (Regulation of immune } \\
\text { response) }\end{array}$ & 0.000139 & $\begin{array}{l}\text { HLA-A, HLA-C, HLA-DQB2, } \\
\text { HLA-DRB1, MARCO, } \\
\text { MICA, NFKBIL1 }\end{array}$ \\
\hline $\begin{array}{l}\text { GO:0006952: Savunma tepki- } \\
\text { sinin düzenlenmesi } \\
\text { (Regulation of defense } \\
\text { response) }\end{array}$ & 0.000172 & $\begin{array}{l}\text { HLA-A, S100A8, S100A9, } \\
\text { MARCO, MICA, NFKBIL1 }\end{array}$ \\
\hline $\begin{array}{l}\text { GO:0019221: Sitokin aracılı } \\
\text { sinyal yolağı (Cytokine- } \\
\text { mediated signaling pathway) }\end{array}$ & 0.000337 & $\begin{array}{l}\text { HLA-A, HLA-C, HLA-DQB2, } \\
\text { HLA-DRB1, AGPAT1 }\end{array}$ \\
\hline $\begin{array}{l}\text { GO:0050906: Uyaranların } \\
\text { tespiti (Detection of stimulus) }\end{array}$ & 0.000426 & $\begin{array}{l}\text { HLA-A, HLA-DRB1, RHO, } \\
\text { TTN }\end{array}$ \\
\hline $\begin{array}{l}\text { GO:0002253:Immün yanıtın } \\
\text { aktivasyonu (Activation of } \\
\text { immune response) }\end{array}$ & 0.000454 & $\begin{array}{l}\text { HLA-DQB2, HLA-DRB1, } \\
\text { MARCO, MICA, NFKBIL1 }\end{array}$ \\
\hline $\begin{array}{l}\text { GO:0002376: Immün sistem } \\
\text { sürecinin düzenlenmesi } \\
\text { (Regulation of immune) }\end{array}$ & 0.000504 & $\begin{array}{l}\text { HLA-A, HLA-C, HLA-DQB2, } \\
\text { HLA-DRB1, MARCO, } \\
\text { MICA, NFKBIL1, HSPA1B }\end{array}$ \\
\hline
\end{tabular}

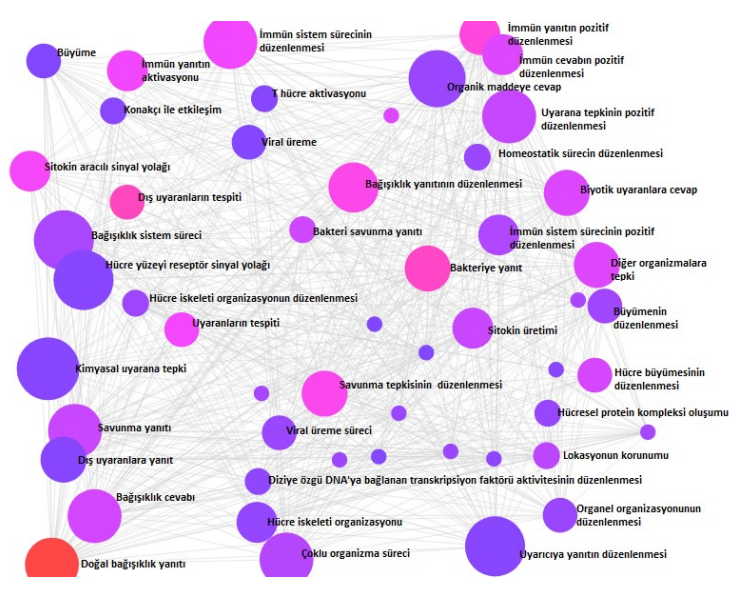

Sekil 3.

Ortak DEG'lerin kümelendikleri GO biyolojik süreçler $(p<0.05)$. Dairenin büyüklüğ̈̈ ilgili yolağın anlamlılık derecesiyle doğru orantılıdır. Kırmızı daire en anlamlı yolă̆l gösterir.

\subsection{HCC ve LOAD için ortak miRNA regülatörlerinin tespiti}

Hub genleri ortak olarak regüle eden miRNA'ların tahmin analizleri mirDIP veritabanı kullanılarak yapıldı. MirDIP'teki analizlerimiz, iki veya daha fazla 


\section{LOAD ve HCC İle İlişkili Ortak Moleküler Yolaklar}

hub geni regüle etme potansiyeli olan yüksek skorlu 40 miRNA tespit edildi. Beş miRNA (hsa-miR-143-3p, hsa-miR-148a-3p, hsa-miR-148b-3p, hsa-miR-152-3p, hsa-miR-939-5p) önerilen hub genler için varsayılan ortak anahtar miRNA regülatörü olarak öngörülmüştür. Hub genlerinin en az dördünün ekspresyonunu regüle ettiği tahmin edilen ortak HCC ve LOAD miRNA regülatörleri Tablo VI'da gösterilmiştir.

Tablo VI. LOAD ve HCC ile ilişkili hub genlerin miRNA regulatorleri

\begin{tabular}{|l|l|}
\hline miRNA ID & Hub genes \\
\hline hsa-miR-143-3p & $\begin{array}{l}\text { HLA-A, HLA-C, HLA-DQB2, } \\
\text { HLA-DRB1, TRIM31 }\end{array}$ \\
\hline $\begin{array}{l}\text { hsa-miR-148a-3p, hsa-miR-148b-3p, hsa- } \\
\text { miR-152-3p }\end{array}$ & $\begin{array}{l}\text { HLA-A, HLA-C, HLA-DQB2, } \\
\text { HLA-DRB1 }\end{array}$ \\
\hline hsa-miR-939-5p & $\begin{array}{l}\text { HLA-A, HLA-C, HLA-DQB2, } \\
\text { TRIM31 }\end{array}$ \\
\hline $\begin{array}{l}\text { hsa-miR-1207-5p, hsa-miR-125b-5p, hsa- } \\
\text { miR-486-3p }\end{array}$ & HLA-DQB2, HLA-DRB1 \\
\hline $\begin{array}{l}\text { hsa-miR-136-5p, hsa-miR-494-3p, hsa-miR- } \\
767-5 p, \text { hsa-miR-873-5p, hsa-miR-22-5p }\end{array}$ & HLA-A, HLA-DRB1 \\
\hline $\begin{array}{l}\text { hsa-miR-181c-5p, hsa-miR-654-5p, hsa-miR- } \\
760\end{array}$ & HLA-C, HLA-DQB2 \\
hsa-miR-185-5p, hsa-miR-622 & HLA-C, TRIM31 \\
\hline hsa-miR-197-3p & HLA-DQB2, TRIM31 \\
$\begin{array}{l}\text { hsa-miR-2110, hsa-miR-224-5p, hsa-miR- } \\
\text { 23a-3p, hsa-miR-23b-3p, hsa-miR-205-5p, } \\
\text { hsa-miR-301a-3p, hsa-miR-423-5p, hsa-miR- } \\
\text { 491-5p, hsa-miR-500a-3p, hsa-miR-518c-5p, } \\
\text { hsa-miR-608, hsa-miR-1299, hsa-miR-1293, } \\
\text { hsa-miR-130a-3p, hsa-miR-130b-3p, hsa- } \\
\text { miR-149-3p, hsa-miR-1224-3p }\end{array}$ & \\
\hline $\begin{array}{l}\text { hsa-miR-298 } \\
\text { hsa-miR-330-5p, hsa-miR-942-5p, hsa-miR- } \\
\text { 326 }\end{array}$ & HLA-A, HLA-DQB2 \\
\hline
\end{tabular}

\section{Tartışma ve Sonuç}

AH, dünya çapında yüksek mortalite ve mortalite oranlarına yol açan tedavi edilemez hastalıklardan biridir. Genomik tıptaki ilerlemeye ve $\mathrm{AH}$ patofizyolojisi ile bilgi birikimine rağmen hastalığın etiyolojisinin altında yatan sebepler hala araştırılması gerekmektedir. Bu nedenle, $\mathrm{AH}$ erken teşhisinde kullanmak ve yeni terapötik yaklaşımlar geliştirmek için yeni biyobelirteçleri tanımlamaya acil ihtiyaç vardır. Son yıllarda, biriken kanitlar AH ile kanser arasinda bir bağlantı olduğunu düşündürmektedir ve bu da her iki hastalığın ortak moleküler etiyolojisinin araştırılmasının AH patogeneziyle ilgili umut verici biyobelirteçleri ortaya çıkarabileceğini göstermektedir. $\mathrm{Bu}$ alanda yapılan araştırmaların bazı sınırlamaları ve çelişkili sonuçları olmasına rağmen, çeşitli çalışmalar AH ve farklı kanser türleri arasında ters bir ilişki olduğunu göstermektedir ${ }^{37,38,39,40,41}$. Bununla birlikte, AH ve HCC arasındaki bağlantıya ait yeterli çalışma yoktur. HCC en yaygın karaciğer malignitesidir ve devam eden çabalar sağkalım oranlarını arttırmak ve toplumlardaki hastalık yükünü hafifletmek için hassas moleküler biyobelirteçler geliştirmeyi amaçlamakta$\mathrm{dir}^{42}$.

$\mathrm{Bu}$ çalışmada, AH ve HCC patofizyolojisinin altında yatan ortak moleküler mekanizma biyoinformatik araçlarla araştırıldı. İn siliko yaklaşımla tasarlanan çalışmamızın temel amacı, bu alanda tedavi yaklaşımları ve hastalık yönetimi için araştırmacılara in siliko kanıt sunarak deneysel araştırmalara ön veri oluşturmaktır.

$\mathrm{Bu}$ doğrultuda, AH'nın yaygın tipi olan LOAD ve HCC ile ilişkili RNA-seq veri setleri GEO veri tabanından alınarak analiz edildi. Her iki hastalıkta da ortak DEG'ler tanımlandı ve bunların moleküler yolaklarda ve biyolojik süreçlerde işlevlerini tanımlamak için fonksiyon zenginleştirme analizleri yapıldı. Bu analizler, ortak DEG'lerin bağışıklık tepkisi ve bununla ilgili hücresel süreçler üzerindeki varsayılan etkilerine 1şık tutmaktadır. PPE ağı ve hub gen analizlerimiz, ağda yüksek derecelere sahip 5 hub geni (HLA-DRB1, $H L A-D Q B 2$, TRIM31, HLA-C, HLA-A) ortaya ç1kard1. $H L A-D R B 1$ ve $H L A-A$ 'nın her iki veri setinde de aynı yönde düzenlendiği gözlenmiştir, ancak diğer hub genlerin iki hastalığa ait veri setlerinde zit yönlerde regüle edildikleri gözlenmiştir. Özellikle belirtmek gerekir ki, bahsedilen genler bağışıklık tepkisinin iyi bilinen aracılarıdır; $\mathrm{AD}^{43-45}$ ve $\mathrm{HCC}^{46-48}$ dahil olmak üzere enflamasyon ile ilişkili hastalıkların patogenezinde önemli rol oynadıkları bilinmektedir. Ayrıca, tespit edilen hub genlerinin de içinde bulunduğu majör doku-uyumluluk kompleksi (MHC) genlerinin tümör gelişimi ve metastazındaki rolleri geniş çapta araştırılmaktadır ve kanser tedavisinde immünoterapi uygulamaları için hedef moleküller olarak önerilmektedir ${ }^{49,50,51}$. Aynı zamanda nörodejenerasyona bağlı immun cevabın da $\mathrm{AH}$ patogenezinde önemli rolü olduğu bilinmektedir ${ }^{52-55}$. Diğer hub olarak önerdiğimiz TRIM31 (E3 UbiquitinProtein Ligase) geni ayrıca, doğuştan gelen bağışıklık tepkisi ve kanser metabolizmasındaki önemli rolü nedeniyle HCC'de teropatik hedef olarak gösterilmektedir $^{56}$. Analizlerimizde LOAD veri setinde aşağıregüle olduğu gözlenen TRIM31 geni daha önceki çalışmalarla AH'de aktif olan NLRP3 inflamazomunun inhibitörü olarak gösterilmiştir $^{57,58}$. Bu bağlamda, kanser tedavisinde TRIM31'i hedef alan terapotik yaklaşımlar kişilerde $\mathrm{AH}$ gelişme riskini artırabileceği değerlendirilerek özenle uygulanmalidir.

Ek olarak, LOAD ve HCC için ortak anahtar biyobelirteçleri belirleme çabalarımız, her iki hastalıkta da hub olarak önerilen genlerin regülasyonunda önemli olması olası 40 miRNA'yı ortaya çıkarmıştır (Tablo VI). Gen ekspresyonunun post-translasyonel regülasyonunda görevli miRNA'ların kanser ve nörodejeneratif hastalıklar da dahil olmak üzere bir çok hastalığın patogenezine önemli katkıları olduğu 
bilinmektedir ${ }^{59-61}$. Ortak hub genlerini düzenlemesinde rolü olduğu tahmin edilen miRNA'lar arasinda olan "miR-143-3p" beş hub geninin hepsinin hedef regülatörü olma potansiyeli açısından iki hastalık için ortak anahtar miRNA olarak düşünülmektedir. Bu sonucumuz HCC ve AH'de miRNA-143'ün düzensiz ekspresyonunu gösteren önceki çalışmaların sonuçları ile de uyumludur ${ }^{62,63,64}$. MiRNA-143'ün LOAD ve HCC'deki olası ortak rolü ileriki çalışmalarla aydınlatılmalıdır.

Çalışmamızda toplum sağlığı açısından önemli iki hastalığın ortak mekanizmasına ait in siliko bulgularımız yeni araştırmalara yön verme açısından son derece önemlidir. Bu alanda Lai ve ark. tarafindan yapılan bir araştırmada yeni HCC tanısı konmuş kişiler ve HCC olmayan kontrol grubu arasında $\mathrm{AH}$ komorbiditesi istatiksel olarak hesaplanmış ve iki hastalık arasında anlamlı bir korelasyon saptanmamış$\operatorname{tır}^{65}$. Önemle belirtmek gerekir ki bu çalışma metodoloji açısından iki hastalık arasında ortak bir mekanizma olmadığını savunmak için yeterli kanıtlara sahip değildir. HCC tanısı konmuş bireyleri ve eşleşen kontrolleri uzun dönemde takip ederek $\mathrm{AH}$ oluşma riskinin gözlenmesi ile bu iki hastalık arasındaki korelasyonun gözlenmesi ile daha anlamlı sonuçlara ulaşılabilir.

Bununla beraber bizim çalışmamızın sonuçlarını destekler nitelikteki güncel bir derlemede ise karaciğer disfonksiyonunun $\mathrm{AH}$ oluşumuna zemin hazırlayacak moleküler yolakları etkileyebileceği tartışılmıştır ${ }^{66} . \mathrm{Bu}$ çelişen sonuçların güçlü metodolojilerle düzenlenmiş epidemiyolojik ve omik çalışmalarla daha fazla araşt1rılmas1 gerekmektedir.

Bu çalışmanın in siliko tasarımından kaynaklı ve sonuçlarımızın deneysel olarak test edilmediği için bazı sınırlamaları vardır. Ancak bulgularımız, metodolojimizin ve analizlerimizin güçlü yönlerini destekleyen literatürle son derece uyumludur. Önemle not etmek isteriz ki, bu sonuçların iki hastalığın moleküler epidemiyolojisindeki ortak katkılarını aydınlatmak için bağımsız veri setlerinde değerlendirme yapılması gerekir.

Sonuç olarak, bulgularımız HCC ve LOAD patogenezde ortak yolakların ve moleküler biyobelirteçlerin olduğunu ve bunların her iki hastalık için risk değerlendirmesinde ve terapötik uygulamalar geliştirirken dikkate alınması gerektiğini önermektedir Mevcut çalışmanın in siliko bulgularının ileri deneysel araştırmalarla da doğrulanması gerekmektedir ve ileriki çalışmalarla desteklenen sonuçlarının ilaç yeniden amaçlandırma araştırmalarına da veri oluşturma potansiyeli vardır.

\section{Etik Kurul Bilgisi:}

Araştırmamızda Etik Kurulu onayı gerektiren hiçbir insan/hayvan örneği kullanılmamıştır. Analizlerde kullanılan veri setleri araştırmacıların farklı analizlerine olanak sağlamak amacıyla halka açık erişimli sunulan NCBI GEO veri tabanından indirilmiş dolayısıyla etik kurul onayı gerekmemektedir.

\section{Kaynaklar}

1. Uddin MS, Ashraf GM. Introductory Chapter: Alzheimer's Disease-The Most Common Cause of Dementia. Advances in Dementia Research, London: IntechOpen; 2019. 1-8.

2. Bekris LM, Yu CE, Bird TD, et al. Genetics of Alzheimer disease. J Geriatr Psychiatry Neurol 2010;23(4):213-27.

3. Goldman JS, Hahn SE, Catania JW, et al. American College of Medical Genetics and the National Society of Genetic Counselors. Genetic counseling and testing for Alzheimer disease: joint practice guidelines of the American College of Medical Genetics and the National Society of Genetic Counselors. Genet Med 2011;13(6):597-605.

4. Kunkle BW, Grenier-Boley B, Sims R, et al. Alzheimer Disease Genetics Consortium (ADGC); European Alzheimer's Disease Initiative (EADI), Cohorts for Heart and Aging Research in Genomic Epidemiology Consortium (CHARGE), Genetic and Environmental Risk in AD/Defining Genetic, Polygenic and Environmental Risk for Alzheimer's Disease Consortium (GERAD/PERADES), Genetic meta-analysis of diagnosed Alzheimer's disease identifies new risk loci and implicates $A \beta$, tau, immunity and lipid processing. Nat Genet 2019;51(3):414-430.

5. Ozaki K, Niida S. Genetic Background for Alzheimer's Disease: Knowledge Accumulated from AD GWAS. Brain Nerve 2019;71(10):1039-1051.

6. Alzheimer's Association. 2019 Alzheimer's Disease Facts and Figures. Alzheimers Dement 2019;15(3):321-387.

7. Toledo JB, Arnold M, Kastenmüller G, et al. Alzheimer's Disease Neuroimaging Initiative and the Alzheimer Disease Metabolomics Consortium. Metabolic network failures in Alzheimer's disease: A biochemical road map. Alzheimers Dement 2017;13(9):965-984.

8. Clarke JR, Ribeiro FC, Frozza RL, et al. Metabolic Dysfunction in Alzheimer's Disease: From Basic Neurobiology to Clinical Approaches. J Alzheimers Dis 2018;64(s1):S405-S426

9. Kapogiannis D, Mattson MP. Disrupted energy metabolism and neuronal circuit dysfunction in cognitive impairment and Alzheimer's disease. Lancet Neurol 2011;10(2):187-98.

10. Craft $\mathrm{S}$. The role of metabolic disorders in Alzheimer disease and vascular dementia: two roads converged. Arch Neurol 2009;66(3):300-5.

11. Majd S, Power J, Majd Z. Alzheimer's Disease and Cancer: When Two Monsters Cannot Be Together. Front Neurosci 2019;13:155.

12. Frain L, Swanson D, Cho K, et al. Association of cancer and Alzheimer's disease risk in a national cohort of veterans. Alzheimers Dement 2017;13(12):1364-1370.

13. Musicco M, Adorni F, Di Santo S, et al. Inverse occurrence of cancer and Alzheimer disease: a population-based incidence study. Neurology 2013 23;81(4):322-8.

14. Driver JA, Beiser A, Au R, et al. Inverse association between cancer and Alzheimer's disease: results from the Framingham Heart Study. BMJ 2012;344:e1442.

15. Catalá-López F, Suárez-Pinilla $\mathrm{M}$, Suárez-Pinilla $\mathrm{P}$, et al. Inverse and direct cancer comorbidity in people with central nervous system disorders: a meta-analysis of cancer incidence in 577,013 participants of 50 observational studies. Psychother Psychosom 2014;83(2):89-105.

16. Roe CM, Behrens MI, Xiong C, et al. Alzheimer disease and cancer. Neurology 2005;64(5):895-8.

17. Roe CM, Fitzpatrick AL, Xiong C, et al. Cancer linked to Alzheimer disease but not vascular dementia. Neurology 2010;74(2):106-12.

18. Ou SM, Lee YJ, Hu YW, et al. Does Alzheimer's disease protect against cancers? A nationwide population based study. Neuroepidemiology 2013;40(1):42-9. 


\section{LOAD ve HCC İle İlişkili Ortak Moleküler Yolaklar}

19. Lee JE, Kim D, Lee JH. Association between Alzheimer's Disease and Cancer Risk in South Korea: an 11-year Nationwide Population-Based Study. Dement Neurocogn Disord 2018;17(4):137-147.

20. Zhang Q, Guo S, Zhang X, et al. Inverse relationship between cancer and Alzheimer's disease: a systemic review metaanalysis. Neurol Sci 2015;36(11):1987-94.

21. Shafi O. Inverse relationship between Alzheimer's disease and cancer, and other factors contributing to Alzheimer's disease: a systematic review. BMC Neurol 2016;16(1):236.

22. Nudelman KNH, McDonald BC, Lahiri DK, Saykin AJ Biological Hallmarks of Cancer in Alzheimer's Disease. Mol Neurobiol 2019;56(10):7173-7187.

23. Behrens MI, Lendon C, Roe CM. A common biological mechanism in cancer and Alzheimer's disease? Curr Alzheimer Res 2009;6(3):196-204.

24. Lehrer S. Glioma and Alzheimer's Disease. J Alzheimers Dis Rep 2018;2(1):213-218.

25. Lehrer S, Rheinstein PH. Alzheimer's Disease Susceptibility Genes in Malignant Breast Tumors. Cancer Transl Med 2019;5(2):42-46

26. Holohan KN, Lahiri DK, Schneider BP, Foroud T, Saykin AJ Functional microRNAs in Alzheimer's disease and cancer: differential regulation of common mechanisms and pathways. Front Genet 2013;3:323

27. Nagaraj S, Zoltowska KM, Laskowska-Kaszub K, Wojda U microRNA diagnostic panel for Alzheimer's disease and epigenetic trade-off between neurodegeneration and cancer. Ageing Res Rev 2019;49:125-143.

28. Monacelli F, Cea M, Borghi R, Odetti P, Nencioni A. Do Cancer Drugs Counteract Neurodegeneration? Repurposing for Alzheimer's Disease. J Alzheimers Dis 2017;55(4):1295-1306.

29. Vargas DM, De Bastiani MA, Zimmer ER, Klamt F. Alzheimer's disease master regulators analysis: search for potential molecular targets and drug repositioning candidates. Alzheimers Res Ther 2018;10(1):59.

30. Clough E, Barrett T. The Gene Expression Omnibus Database Methods Mol Biol 2016;1418:93-110.

31. Mahi NA, Najafabadi MF, Pilarczyk M, Kouril M, Medvedovic M. GREIN: An Interactive Web Platform for Re-analyzing GEO RNA-seq Data. Sci Rep 2019;9(1):7580.

32. Szklarczyk D, Gable AL, Lyon D, et al. STRING v11: proteinprotein association networks with increased coverage, supporting functional discovery in genome-wide experimental datasets. Nucleic Acids Res 2019;47(D1):D607-D613.

33. Chin $\mathrm{CH}$, Chen $\mathrm{SH}$, Wu HH, Ho CW, Ko MT, Lin CY. cytoHubba: identifying hub objects and sub-networks from complex interactome. BMC Syst Biol 2014;8 Suppl 4:S11.

34. Ideker T, Sharan R. Protein networks in disease. Genome Res 2008;18(4):644-52

35. Xia J, Gill EE, Hancock RE. NetworkAnalyst for statistical, visual and network-based meta-analysis of gene expression data. Nat Protoc 2015;10(6):823-44.

36. Tokar T, Pastrello C, Rossos AEM, et al. mirDIP 4.1integrative database of human microRNA target predictions. Nucleic Acids Res 2018;46(D1):D360-D370.

37. Seddighi S, Houck AL, Rowe JB, Pharoah PDP. Evidence of a Causal Association Between Cancer and Alzheimer's Disease: a Mendelian Randomization Analysis. Sci Rep 2019;9(1):13548.

38. Ibáñez $\mathrm{K}$, Boullosa $\mathrm{C}$, Tabarés-Seisdedos $\mathrm{R}$, Baudot $\mathrm{A}$, Valencia A. Molecular evidence for the inverse comorbidity between central nervous system disorders and cancers detected by transcriptomic meta-analyses. PLoS Genet 2014;10(2):e1004173.

39. Lehrer S, Rheinstein PH. Alzheimer's Disease Susceptibility Genes in Malignant Breast Tumors. Cancer Transl Med 2019;5(2):42-46
40. Sánchez-Valle J, Tejero H, Ibáñez K, et al. A molecular hypothesis to explain direct and inverse co-morbidities between Alzheimer's Disease, Glioblastoma and Lung cancer Sci Rep 2017;7(1):4474.

41. Battaglia C, Venturin M, Sojic A, et al. Candidate Genes and MiRNAs Linked to the Inverse Relationship Between Cancer and Alzheimer's Disease: Insights From Data Mining and Enrichment Analysis. Front Genet 2019;10:846.

42. Tunissiolli NM, Castanhole-Nunes MMU, Biselli-Chicote PM, et al. Hepatocellular Carcinoma: a Comprehensive Review of Biomarkers, Clinical Aspects, and Therapy. Asian Pac J Cancer Prev 2017;18(4):863-872.

43. Kinney JW, Bemiller SM, Murtishaw AS, Leisgang AM, Salazar AM, Lamb BT. Inflammation as a central mechanism in Alzheimer's disease. Alzheimers Dement (N Y) 2018;4:575590.

44. Newcombe EA, Camats-Perna J, Silva ML, Valmas N, Huat TJ, Medeiros R. Inflammation: the link between comorbidities, genetics, and Alzheimer's disease. $\mathrm{J}$ Neuroinflammation 2018;15(1):276

45. Heppner FL, Ransohoff RM, Becher B. Immune attack: the role of inflammation in Alzheimer disease. Nat Rev Neurosci 2015;16(6):358-372.

46. Keenan BP, Fong L, Kelley RK. Immunotherapy in hepatocellular carcinoma: the complex interface between inflammation, fibrosis, and the immune response. J Immunother Cancer 2019;7(1):267.

47. Bishayee A. The role of inflammation and liver cancer. Adv Exp Med Biol 2014;816:401-435.

48. Yu LX, Ling Y, Wang HY. Role of nonresolving inflammation in hepatocellular carcinoma development and progression. NPJ Precis Oncol 2018;2(1):6.

49. Garrido C, Paco L, Romero I, et al. MHC class I molecules act as tumor suppressor genes regulating the cell cycle gene expression, invasion and intrinsic tumorigenicity of melanoma cells. Carcinogenesis 2012;33(3):687-693.

50. Garrido F. MHC/HLA Class I Loss in Cancer Cells. Adv Exp Med Biol 2019;1151:15-78.

51. Axelrod ML, Cook RS, Johnson DB, Balko JM. Biological Consequences of MHC-II Expression by Tumor Cells in Cancer. Clin Cancer Res 2019;25(8):2392-2402.

52. Ciccocioppo F, Lanuti P, Pierdomenico L, et al. The Characterization of Regulatory T-Cell Profiles in Alzheimer's Disease and Multiple Sclerosis. Sci Rep 2019;9(1):8788.

53. Chitnis T, Weiner HL. CNS inflammation and neurodegeneration. J Clin Invest 2017;127(10):3577-3587.

54. Nataf S. Autoimmunity as a Driving Force of Cognitive Evolution. Front Neurosci 2017;11:582.

55. Baruch K, Rosenzweig N, Kertser A, et al. Breaking immune tolerance by targeting Foxp3 $(+)$ regulatory $\mathrm{T}$ cells mitigates Alzheimer's disease pathology. Nat Commun 2015;6:7967.

56. Guo P, Ma X, Zhao W, et al. TRIM31 is upregulated in hepatocellular carcinoma and promotes disease progression by inducing ubiquitination of TSC1-TSC2 complex. Oncogene 2018;37(4):478-488.

57. Yang Y, Wang H, Kouadir M, Song H, Shi F. Recent advances in the mechanisms of NLRP3 inflammasome activation and its inhibitors. Cell Death Dis 2019;10(2):128

58. Yin J, Zhao F, Chojnacki JE, et al. NLRP3 Inflammasome Inhibitor Ameliorates Amyloid Pathology in a Mouse Model of Alzheimer's Disease. Mol Neurobiol 2018;55(3):1977-1987.

59. Danborg PB, Simonsen AH, Waldemar G, Heegaard NH. The potential of microRNAs as biofluid markers of neurodegenerative diseases-a systematic review. Biomarkers 2014;19(4):259-268.

60. Van Giau V, An SS. Emergence of exosomal miRNAs as a diagnostic biomarker for Alzheimer's disease. J Neurol Sci 2016;360:141-152. 


\section{Pirim ve E.B. Yılmaz}

61. Tan W, Liu B, Qu S, Liang G, Luo W, Gong C. MicroRNAs and cancer: Key paradigms in molecular therapy. Oncol Lett 2018;15(3):2735-2742.

62. Zhang ZQ, Meng H, Wang N, et al. Serum microRNA 143 and microRNA 215 as potential biomarkers for the diagnosis of chronic hepatitis and hepatocellular carcinoma. Diagn Pathol 2014;9:135.

63. Dong H, Li J, Huang L, et al. Serum MicroRNA Profiles Serve as Novel Biomarkers for the Diagnosis of Alzheimer's Disease. Dis Markers 2015;2015:625659.

64. Cheng L, Doecke JD, Sharples RA, et al. Australian Imaging, Biomarkers and Lifestyle (AIBL) Research Group. Prognostic serum miRNA biomarkers associated with Alzheimer's disease shows concordance with neuropsychological and neuroimaging assessment. Mol Psychiatry 2015;20(10):1188-1196.

65. Lai SW, Chen HJ, Lin CL, Liao KF. No correlation between Alzheimer's disease and risk of hepatocellular carcinoma in older people: an observation in Taiwan. Geriatr Gerontol Int 2014;14(1):231-232.

66. Estrada LD, Ahumada P, Cabrera D, Arab JP. Liver Dysfunction as a Novel Player in Alzheimer's Progression: Looking Outside the Brain. Front Aging Neurosci 2019;11:174. 